\title{
Hair and Scalp Disorders in a Tuscan Pediatric Dermatological Outpatient Clinic: A Clinical and Epidemiological Evaluation
}

\author{
Rossana Conti ${ }^{a}$ Roberta Colucci ${ }^{a}$ Meena Arunachalam ${ }^{a}$ Samantha Berti ${ }^{a}$ \\ Caterina Fabroni $^{a}$ Maurizio De Martino ${ }^{b}$ Federica Dragonia ${ }^{a}$ Linda Lazzeri $^{a}$ \\ Lisa Pisaneschi ${ }^{a}$ Silvia Moretti ${ }^{a}$ \\ a Section of Dermatology, Department of Surgery and Translational Medicine, University of Florence, and ${ }^{\text {b Pediatric }}$ \\ Dermatology Service of Anna Meyer Pediatric Hospital of Florence, Department of Women's and Children's Health, \\ University of Florence, Florence, Italy
}

\section{Key Words}

Dermatology $\cdot$ Hair and scalp disorders · Alopecia

\begin{abstract}
Objectives: The aim of this study was to evaluate the clinical and epidemiological profile of hair and scalp disorders in children referred to the Pediatric Dermatology Outpatient Clinic. Materials and Methods: We performed a retrospective study of children with hair loss problems or scalp diseases who turned to the Pediatric Dermatology Service, Anna Meyer Pediatric Hospital, Florence, Italy, from January 1, 2009, to December 31, 2009. Demographics, personal and familial medical history, laboratory tests, clinical examination, final diagnosis and therapeutic interventions were obtained from the manual chart review. Results: Of the 2,640 children who had access to the Pediatric Dermatology Service, 190 (7.19\%) had a hair or scalp disorder. Among the 190 children, 60 (31.57\%) presented with nonscarring alopecia, $56(29.47 \%)$ had benign neoplasias, hamartomas or vascular malformations of the scalp, 51 (26.84\%) had scalp inflammatory diseases, 14 (7.36\%) had scarring alopecia, 5 (2.63\%) had infections and $2(1.05 \%)$ had infestation of the scalp. A case of constitutional hypertrichosis (0.52\%) and also a case
\end{abstract}

\begin{tabular}{ll}
\hline KARGER & $\begin{array}{l}\text { ( } 2015 \text { S. Karger AG, Basel } \\
1011-7571 / 15 / 0251-0067 \$ 39.50 / 0\end{array}$ \\
E-Mail karger@karger.com & $\begin{array}{l}\text { This is an Open Access article licensed under the terms of the } \\
\text { www.karger.com/mpp }\end{array}$ \\
$\begin{array}{l}\text { Creative Commons Attribution-NonCommercial 3.0 Un- } \\
\text { ported license (CC BY-NC) (www.karger.com/OA-license), } \\
\text { applicable to the online version of the article only. Distribu- } \\
\text { tion permitted for non-commercial purposes only. }\end{array}$
\end{tabular}

(0.52\%) of lamellar ichthyosis were diagnosed. Conclusions: Our results underline that hair and scalp diseases represent an important percentage of admittances to a dermatological pediatric outpatient clinic. The variety and complexity of the diseases observed in this study included diseases commonly found also in adulthood.

(c) 2015 S. Karger AG, Basel

\section{Introduction}

Hair and scalp disorders in infants and children are a common occurrence and may constitute a complex clinical problem, and they are also a source of anxiety and concern for patients and families [1]. Hair disorders in children can be congenital or acquired and may be associated or not with defects in hair structure. In some cases, they may be a part of serious hereditary syndromes [2].

To the best of our knowledge, no extensive report exists regarding the epidemiology of these disorders in children $[3,4]$. Therefore, we sought to evaluate the clinical and epidemiological profile of hair and scalp disorders in children referred to the Pediatric Dermatology Outpatient Clinic. 
Table 1. Proportions (numbers with percentages) of scalp and hair diseases of 190 children

\begin{tabular}{|c|c|}
\hline Scalp and hair diseases & Number (\%) \\
\hline Nonscarring alopecia & $60(31.57)$ \\
\hline Alopecia areata & $35(18.42)$ \\
\hline Tinea capitis & $10(5.26)$ \\
\hline Trichotillomania & $8(4.21)$ \\
\hline Androgenetic alopecia & $5(2.63)$ \\
\hline Traction alopecia & $1(0.52)$ \\
\hline Temporal triangular alopecia & $1(0.52)$ \\
\hline \multicolumn{2}{|c|}{ Vascular malformations and neoplasias or } \\
\hline hamartomas & $56(29.47)$ \\
\hline Hemangiomas & $20(10.52)$ \\
\hline Sebaceous nevi & $16(8.42)$ \\
\hline Melanocytic nevi & $13(6.84)$ \\
\hline Sebaceous cysts & $3(1.57)$ \\
\hline Pyogenic granuloma & $2(1.05)$ \\
\hline Trichoepithelioma & $1(0.52)$ \\
\hline Isolated mastocytoma & $1(0.52)$ \\
\hline Hair scalp inflammatory diseases & $51(26.84)$ \\
\hline Psoriasis & $29(15.26)$ \\
\hline Seborrheic dermatitis & $22(11.57)$ \\
\hline Scarring alopecia & $14(7.36)$ \\
\hline Aplasia cutis & $9(4.73)$ \\
\hline Posttraumatic alopecia & $4(2.10)$ \\
\hline Discoid lupus erythematosus & $1(0.52)$ \\
\hline Infections and infestations & $7(3.68)$ \\
\hline Molluscum contagiosum & $4(2.10)$ \\
\hline Head lice & $2(1.05)$ \\
\hline Impetigo & $1(0.52)$ \\
\hline Others & $2(1.05)$ \\
\hline Constitutional hypertrichosis & $1(0.52)$ \\
\hline Lamellar ichthyosis & $1(0.52)$ \\
\hline
\end{tabular}

\section{Materials and Methods}

We performed a retrospective study and reviewed medical records of all children between 0 and 16 years, who had access to the Pediatric Dermatology Service, Anna Meyer Pediatric Hospital, Florence, Italy, for hair loss problems or scalp diseases from January 1,2009 , to December 31,2009. The data gleaned from medical records included personal and familial history, clinical examination, possible laboratory evaluations, final diagnosis and therapeutic interventions. The study design was approved by the Local Institutional Review Board.

\section{Results}

Of the 2,640 children who had access to the Dermatology Service in 2009, 190 (7.19\%) had a hair or scalp disorder; all the patients were Caucasian except 2 African brothers. The 190 children had the following presenta- tions: nonscarring alopecia, 60 (31.57\%); benign neoplasias, hamartomas or vascular malformations of the scalp, 56 (29.47\%); scalp inflammatory diseases, 51 (26.84\%); 14 (7.36\%) presented scarring alopecia; $5(2.63 \%)$ had infection and $2(1.05 \%)$ infestation of the scalp. Finally, a case $(0.52 \%)$ of constitutional hypertrichosis in a 3-year-old baby girl and 1 case $(0.52 \%)$ of lamellar ichthyosis in a 2 -year-old boy were diagnosed.

Of all the cases of nonscarring alopecia, the most frequent was alopecia areata, (35, i.e. $58.3 \%)$, most of which $(27$, i.e. $77.1 \%)$ were mild, while 6 were severer and 2 cases were total, one of which was associated with 20 -nail dystrophy (trachyonychia). Ten cases of tinea capitis, 8 cases of trichotillomania and 5 cases of 'diffuse' androgenetic alopecia (AGA) were detected in children aged from 6 to 16 years ( 2 girls and 3 boys). Three out of 5 AGA cases we observed had a family history and showed a rapid progression of the disease. Moreover, 1 case of traction alopecia and another case of temporal triangular alopecia were also diagnosed (table 1 ).

Fifty-six (29.47\%) children had benign neoplasias, hamartomas or vascular malformations of the scalp (table 1).

In regard to hair scalp inflammatory disorders (26.84\%), 29 cases of psoriasis (12 cases of pseudotinea amiantacea and 17 cases of plaque-type psoriasis) and 22 cases of seborrheic dermatitis (4 cases in newborns and 18 cases in children older than 1 year) were observed.

In contrast, scarring alopecia was observed in 14 patients (7.36\%). Nine of them had a single patch of alopecia due to aplasia cutis congenita on the scalp.

In addition, 4 cases of posttraumatic alopecia and 1 case of discoid lupus erythematosus were observed (table 1).

Among infestations or infections of the scalp, 4 cases of molluscum contagiosum, 2 cases of head lice and 1 case of impetigo were recorded (table 1).

\section{Discussion}

In this study, the prevalence of scalp and/or hair diseases in the pediatric population was remarkable. Alopecia areata was the most common disease among the group of nonscarring alopecia, which led to the most frequent number of examinations (up to 3 a year) per patient, probably because of the significant psychological impact this disease had on the children and their family. In these patients, the triggering event was an acute stress such as the birth of a sibling, parental divorce or death of a close individual, necessitating a specific psychological counsel- 
ing. In this study, the $1.32 \%$ prevalence of alopecia is within the range of $1-2 \%$ reported previously [5]. Equally, in our study no association was observed between alopecia areata and autoimmune or immune-mediated diseases as previously reported $[5,6]$. However, in other studies, about $20 \%$ of patients with alopecia areata were reported to have nail changes, with pitting being the most common feature.

The 10 cases of tinea capitis we observed were mainly caused by Microsporum canis, whereas Trichophyton violaceum was isolated only in 2 brothers coming from central Africa, a region where this dermatophyte is common [7]. The isolation of M. canis in our study confirmed the dominance of this dermatophyte in tinea capitis as was seen in southern Spain [8].

In our study, the observation of equal numbers of trichotillomania in males and in females is not consistent with previous reports that describe trichotillomania as a nonscarring alopecia, affecting mostly females [9]. We hypothesize that the atypical sex distribution in our case series may be related to the small sample analyzed. Trichotillomania is defined as an impulse control disorder. Children have an overwhelming urge to pluck out hair, which leads to momentary relief from associated anxiety [9].

In regard to AGA, which is the more common and largely studied hair loss in adults, little is known about its prevalence and characteristics in pediatric populations. The $2.63 \%$ prevalence among subjects with scalp disorder found in our study was lower compared to the $13 \%$ of a previous report [10]. The difference in prevalence could be due to the lower age range in our study (6-16 years) versus the 8-19 years in the previous study [10].

The AGA typically does not affect prepubescent children, because of the absence of androgens at this age. Causes of AGA in this phase of life are not well known, but at least two possibilities have been suggested: an involuntary intake of hormones in the diet or an excessive sensitivity of hair follicles to adrenal hormones. Laboratory examinations were carried out in all our patients affected by this disorder and all results were within the normal range, according to age and sex.

In our case series the only case of traction alopecia was detected in a 6-year-old Caucasian girl, while the majority of the literature has focused on the prevalence of traction alopecia in patients of African ethnicity, because of the particular cultural or cosmetic habits of this population [11]. It is well known that this reversible kind of alopecia is due to the action of tensile forces to the scalp and may lead to a scarring alopecia over time. Indeed, in our case the mother admitted to braid her child's hair daily.
Concerning hemangiomas, the prevalence of $10.52 \%$ confirmed the $10-12 \%$ reported previously [12].

Hemangiomas occur in children of all races, even if they seem to be less common in those of African or Asian descent.

Several cases of sebaceous nevi were found in our case series. Sebaceous nevi, as well as vascular malformations, may be associated with severe disorders, such as the nevus sebaceus syndrome [14], or PHACES syndrome, a neurocutaneous syndrome that consists of segmental facial hemangioma with cerebral malformations, aortic branches/cranial artery anomalies, cardiac defects, eye anomalies or ventral wall defects [15]. In our study, none of the above associations was observed. Neoplastic transformation of sebaceous nevi occurs with an estimated incidence of $10-30 \%$, and the risk of this event increases with age [16]. Our patients underwent a follow-up examination once a year.

In our study, the prevalence of melanocytic nevi among subjects with dermatological scalp lesions was about half of the $11.7 \%$ prevalence reported previously in Barcelona [17]. The difference could be explained by the reduced number of total body nevi in our cases, since these patients presented a number of melanocytic nevi between 0 and 10.

Scalp melanocytic nevi are prone to clinical signs of change during a mean follow-up of 2.8 years [18]; however, none of our cases showed clinical signs of change during a 2-year follow-up.

With regard to scalp inflammatory disorders, our results pointed out that scalp psoriasis is a frequent disease of childhood. Moreover, 12 of 29 cases of psoriasis appeared as pseudotinea amiantacea. This clinical presentation has been variously considered in past years as a manifestation of tinea capitis [19], Darier's disease [20], pityriasis rosea [21], seborrheic dermatitis and psoriasis [22]. In accordance with the current literature [22], we consider pseudotinea amiantacea as a minimal form of psoriasis; our diagnosis was supported by a positive family history of psoriasis and the presence of minimal psoriasis in typical sites.

We identified only 4 cases of seborrheic dermatitis, and all of them appeared in the first 3 months of life. The prevalence of seborrheic dermatitis was examined in a population of 1,634 preschool-aged children from Victoria, Australia, and it was found in about $10.0 \%$ [23]. Our percentage might be underestimated because seborrheic dermatitis is often managed by the pediatrician only, without specific dermatological evaluation. Some cases of seborrheic dermatitis may evolve into atopic dermatitis 
in adolescence, but most of them resolve spontaneously [24]. Unfortunately, the duration of our follow-up did not allow us to evaluate whether our patients would develop atopic dermatitis or psoriasis.

Among the scarring alopecia group, aplasia cutis congenita represents the most frequent disorder we observed. In 8 cases these lesions were completely healed at birth and appeared as atrophic scar with alopecia; 1 case of bullous aplasia cutis, a clinical subtype of aplasia cutis congenita, was found. Aplasia cutis congenita is most often a benign isolated defect, but it can be associated with other physical anomalies or malformation syndromes [25]; no case of aplasia cutis was associated with neurological diseases in our cases.

In our study we also observed a (previously diagnosed) case of discoid lupus erythematosus in a 7-year-old child who had a history of scarring alopecia localized in the frontal region. The clinical presentation, at the time of our observation, was stable with negative serological examinations.

With regard to infections, we observed 4 cases of molluscum contagiosum, which is commonly found on the limbs and abdomen [26]. In our cases the infection was localized only on the scalp, and our patients reported to attend school swimming pools, suggesting a possible relationship between the particular location of the lesions and the use of swimming caps, bath sponges or towels.

Only 2 cases of head lice came to our attention, probably because of the monthly dermatological controls carried out in public and private schools in the Florence area in the last 10 years. No recent survey about the epidemiology of head lice exists in Italy, and population-based studies in European countries show highly diverging prevalences, ranging from 1 to $20 \%$, so that our data are not comparable [27].

One limitation of our study is that our results are limited to the Tuscan region and may not be applicable at a national level.

\section{Conclusions}

Our results showed that hair and scalp diseases are a frequent reason of presenting to a dermatological pediatric outpatient clinic. The most common disorder according to our study was nonscarring alopecia accounting for $31.57 \%$ of the diagnosis, and in this group the most frequent disease was alopecia areata, which is usually a benign condition; however, an early diagnosis is important to prevent further hair loss. The second most common disorder was the group of vascular malformation, neoplasia or hamartomas, of which the most representative disease was hemangiomas. Finally, among scalp inflammatory diseases, psoriasis was the most common, and in the scarring alopecia group, aplasia cutis was prevalent.

\section{Disclosure Statement}

There is no conflict of interest.

\section{References}

1 Bedocs LA, Bruckner AL: Adolescent hair loss. Curr Opin Pediatr 2008;20:431-435.

-2 Sarifakioglu E, Yilmaz AE, Gorpelioglu C, et al: Prevalence of scalp disorders and hair loss in children. Cutis 2012;90:225-229.

3 Al-Refu K: Hair loss in children: common and uncommon causes; clinical and epidemiological study in Jordan. Int J Trichol 2013;5:185189.

-4 Nnoruka EN, Obiagboso I, Maduechesi C: Hair loss in children in South-East Nigeria: common and uncommon cases. Int J Dermatol 2007;46(suppl 1):18-22.

5 Hordinsky MK: Overview of alopecia areata. J Investig Dermatol Symp Proc 2013;16:S13S15.

6 Gedik AH, Cakir E, Ozkaya E, et al: Can appropriate diagnosis and treatment of childhood asthma reduce excessive antibiotic usage? Med Princ Pract 2014;23:443-447.
Ginter-Hanselmayer G, Weger W, Ilkit M, et al: Epidemiology of tinea capitis in Europe: current state and changing patterns. Mycoses 2007;50(suppl):P6-P13.

8 Del Boz J, Crespo V, Rivas-Ruiz F, et al: 30year survey of paediatric tinea capitis in southern Spain. J Eur Acad Dermatol Venereol 2011;25:170-174.

-9 Malhotra S, Grover S, Baweja R, et al: Trichotillomania in Children. Indian Pediatr 2008; 45:403-405.

10 Gonzalez ME, Cantatore-Francis J, Orlow SJ: Androgenetic alopecia in the paediatric population: a retrospective review of 57 patients. Br J Dermatol 2010;163:378-385.

11 Samrao A, Chen C, Zedek D, et al: Traction alopecia in a ballerina: clinicopathologic features. Arch Dermatol 2010;146:930-931.
12 Kilcline C, Frieden IJ: Infantile hemangiomas: how common are they? A systematic review of the medical literature. Pediatr Dermatol 2008;25:168-173.

13 Moreno Alonso de Celada R, Floristán Muruzábal U, de Lucas Laguna R: Nevo sebáceo de Jadassohn. An Pediatr (Barc) 2009;70:391.

14 Rubegni P, Poggiali S, Sbano P, et al: A case of sebaceous nevus syndrome (Schimmelpenning-Feuerstein-Mims syndrome). G Ital Dermatol Venereol 2009;144:617-619.

15 Morcillo Azcárate J, Bernabeu-Wittel J, Fernández-Pineda I, et al: PHACES syndrome. Cir Pediatr 2010;23:92-94.

16 Wang Y, Bu WB, Chen H, et al: Basal cell carcinoma, syringocystadenoma papilliferum, trichilemmoma, and sebaceoma arising within a nevus sebaceus associated with pigmented nevi. Dermatol Surg 2011;37:1806-1810. 
17 Aguilera P, Puig S, Guilabert A, et al: Prevalence study of nevi in children from Barcelona. Dermoscopy, constitutional and environmental factors. J Dermatol 2009;218:203-214.

18 Gupta M, Berk DR, Gray C, et al: Morphologic features and natural history of scalp nevi in children. Arch Dermatol 2010;146:506511.

19 Ginarte M, Pereiro M Jr, Fernández-Redondo $\mathrm{V}$, et al: Pityriasis amiantacea as manifestation of tinea capitis due to Microsporum canis. Mycoses 2000;43:93-96.

20 Hussain W, Coulson IH, Salman WD: Pityriasis amiantacea as the sole manifestation of Darier's disease. Clin Exp Dermatol 2009;34: 554-556.
21 Zawar V: Pityriasis amiantacea-like eruptions in scalp: a novel manifestation of pityriasis rosea in a child. Int J Trichol 2010;2:113-115.

22 Abdel-Hamid IA, Agha SA, Moustafa YM, et al: Pityriasis amiantacea: a clinical and etiopathologic study of 85 patients. Int J Dermatol 2003;42:260-264.

23 Foley P, Zuo Y, Plunkett A, et al: The frequency of common skin conditions in preschoolaged children in Australia: seborrheic dermatitis and pityriasis capitis (cradle cap). Arch Dermatol 2003;139:318-322.
24 David TJ, Devlin J, Ewing CI: Atopic and seborrheic dermatitis: practical management. Pediatrician 1991;18:211-217.

25 Frieden IJ: Aplasia cutis congenita: a clinical review and proposal for classification. J Am Acad Dermatol 1986;14:646-660.

26 Braue A, Ross G, Varigos G, et al: Epidemiology and impact of childhood molluscum contagiosum: a case series and critical review of the literature. Pediatr Dermatol 2005;22:287294.

27 Feldmeier H: Pediculosis capitis: new insights into epidemiology, diagnosis and treatment. Eur J Clin Microbiol Infect Dis 2012;31:21052110. 